Review

\title{
Gold Nanorods Based Platforms for Light-Mediated Theranostics
}

\author{
Zhenjiang Zhang, Jing Wang, Chunying Chen ${ }^{凶}$ \\ CAS Key Laboratory for Biomedical Effects of Nanomaterials and Nanosafety, National Center for Nanoscience and Technology, Beijing \\ 100190, China.
}

\begin{abstract}
$\square$ Corresponding author: Dr. Chunying Chen, CAS Key Laboratory for Biomedical Effects of Nanomaterials and Nanosafety, National Center for Nanoscience and Technology (NCNST), No.11, 1st North Street, Zhongguancun, Beijing 100190, China. Tel: +86-10-82545560; Fax: +86-10-62656765; E-mail: chenchy@nanoctr.cn.
\end{abstract}

(c) Ivyspring International Publisher. This is an open-access article distributed under the terms of the Creative Commons License (http://creativecommons.org/ licenses/by-nc-nd/3.0/). Reproduction is permitted for personal, noncommercial use, provided that the article is in whole, unmodified, and properly cited.

Received: 2012.10.18; Accepted: 2013.02.23; Published: 2013.03.0I

\begin{abstract}
Due to their tunable surface plasmon and photothermal effects, gold nanorods (AuNRs) have proved to be promising in a wide range of biomedical applications such as imaging, hyperthermia therapy and drug delivery. All these applications can be remotely controlled by near infrared (NIR) light which can penetrate deep into human tissues with minimal lateral invasion. AuNRs thus hold the potential to combine both imaging diagnosis and therapeutic treatment into one single system and function as a NIR light-mediated theranostic platform. Herein we review recent progress in diagnostic and therapeutic applications of AuNRs with a highlight on combined applications for theranostic purposes.
\end{abstract}

Key words: Gold nanorods, theranostics, cancer therapy, imaging, hyperthermia, drug delivery.

\section{Introduction}

In the classical Chinese epic novel Journey to the West, the most powerful weapon of Monkey King to fight demons is Golden-bound Cudgel which can change its size, stretching to reach the sky, or shrinking to the size of an embroidery needle. Today, scientists in the field of nanotechnology have gained the realistic ability to make gold particles at nanoscale which have proven to be a "magic weapon" to fight human diseases. These gold nanoparticles (AuNPs), such as nanospheres, nanorods, nanoshells, nanostars, and nanocages, are of great interest for bio-imaging and disease therapy due to their remarkable capacity to absorb and scatter light, i. e. due to the localized surface plasmon resonance (SPR) effects [1-2]. Light scattering is used primarily in imaging techniques such as dark-field microscopy [3-4] and optical coherence tomography (OCT) [5-7]. AuNPs also support nonlinear optical imaging, such as two-photon luminescence (TPL) imaging [8-12]. Another unique property of AuNPs is that they can efficiently convert absorbed light to heat through the so called "photothermal effect" [13-15]. The generated heat can be used to enhance contrast in photoacoustic tomography (PAT) imaging [16-19], for hyperthermia therapy [20-22], or to trigger thermo-sensitive release in drug delivery systems [2, 23-24]. In addition, AuNPs are well-known for their nontoxicity, biocompatibility, and chemical inertness [25-26]. All of these properties render AuNPs as a promising platform for various biomedical applications, particularly in cancer diagnosis and therapy.

Due to their anisotropic shapes, gold nanorods (AuNRs) exhibit two distinct SPR bands, a weak transverse SPR band at $\sim 520 \mathrm{~nm}$, similar to that of gold nanospheres, and an intense longitudinal SPR band which can be tuned from visible to near infrared 
(NIR, 650 - $900 \mathrm{~nm}$ ) regions by increasing their aspect ratios [2]. The latter forms the basis for AuNRs' in vivo applications, as NIR light only have minimal absorption by skin and tissue, leading to minimal tissue invasion and deeper (up to $10 \mathrm{~cm}$ ) tissue penetration [13, 27-29]. Compared to most other type of nanostructures, AuNRs have larger extinction coefficients $\left(10^{8}-10^{10} \mathrm{M}^{-1} \mathrm{~cm}^{-1}\right)$ and narrower line-widths, with consequently higher photothermal conversion efficiencies and higher sensitivity to changes in the local dielectric constant [2]. These properties have given rise to many exciting possibilities to employ AuNRs for NIR-resonant biomedical imaging modalities such as TPL, PAT, OCT, and X-ray computed tomography (X-ray CT), and for hyperthermia therapy and gene/drug delivery.

With multiple imaging and therapeutic modalities, AuNRs provide a platform to realize both diagnosis and therapeutic treatment simultaneously in one single system [30-31]. These systems follow on the concept of theranostics, the fusion of therapy and diagnostics for optimizing efficacy and safety of therapeutic regimes (Figure 1). One outstanding advantage of AuNRs-based theranostics over other theranostic platforms is that all the functional modalities can be mediated remotely by NIR light with high spatial and temporal precision.

In this article, we will first discuss the methods for surface modification and functionalization of AuNRs. The imaging applications of AuNRs will only be reviewed briefly since they have recently been discussed in a few excellent review articles [1-2, 15-16, $25,27,32]$. The applications for hyperthermia therapy, as drug delivery vehicles and combined applications with theranostic implications will be discussed in more details.

\section{Surface modification and functionaliza- tion}

The wet chemical seed-mediated synthesis is the most widely used method for AuNRs preparation because it is facile and offers flexible and fine control over aspect ratios [33-35]. AuNRs prepared by this method are coated with the structure-directing surfactant of cetyltrimethylammonium bromide (CTAB) which provides the surface of AuNRs positively charged and thus prevents their aggregation in certain aqueous media via electrostatic repulsion. However, the CTAB-coated AuNRs (CTAB-AuNRs) aggregate rapidly in solutions with high ionic strength such as PBS and cell culture media and CTAB is known to disrupt bio-membrane integrity and thus causes cytotoxicity [36]. Therefore, it is necessary to remove or overcoat the residual CTAB and surface modification is required to prepare stable AuNRs dispersions for various biomedical applications. Dispersion and toxicity issues aside, surface functionalization is often needed to add desirable functionalities such as specific targeting, additional imaging modalities and incorporation of an outer layer for drug delivery. The three most widely used methods for surface modification and functionalization are illustrated in Figure 2.

Due to the strong affinity between thiol and $\mathrm{Au}$, the surface modification of AuNRs for detoxification and stable dispersion is overwhelmingly conducted via $C T A B$ displacement with thiolated species $[25,31]$. The displacement is relatively straightforward, requiring a few hours incubation of AuNRs with an excess amount of thiolated species, such as the most often used thiolated polyethyleneglycol (PEG) [37-39]. As a common strategy for preparing biocompatible nanomaterials, PEG coating helps prevent particle aggregation and non-specific protein adsorption, and allows for longer circulation time in blood stream for greater accumulation in tumors. Our group has found that PDDAC-coated AuNRs exhibit more than 10 folds cellular uptake than CTAB-AuNRs with almost no cytotoxicity [36]. Some typical cytotoxicity results of AuNRs with different surface coatings are summarized in Table 1. Targeting ligands such as RGD peptide [40], folic acids (FA) and deltorphin [41] can be conjugated at the distal end of thiolated PEG for specific interaction with cells and biomolecules to minimize nonspecific cellular uptake which may cause adverse effects to healthy cells. Some other thiolated species have also been used for surface functionalization of AuNRs, such as thiolated DNA for gene therapy $[23,42]$, thiolated peptides for nuclear targeting [43].

Another widely used method for surface modification of AuNRs is layer-by-layer polyelectrolyte absorption that relies on the sequential deposition of anionic, then cationic polyelectrolytes to the AuNRs surface $[2,44]$. In this method, negatively charged polystyrenesulfonate (PSS) is often used as a mild detergent and absorbent to remove CTAB by ultrafiltration and ligand exchange. Cationic polyelectrolytes such as poly(diallyldimethylammonium chloride) (PDDAC or PDADMAC) will then be absorbed on the surface of PSS-coated AuNRs. This method allows for easy control over surface groups for attachment of antibodies, proteins, or other targeting molecules, and surface charges which have a significant effect on cellular uptake and bio-distribution of AuNRs. Our group has found that PDDAC-coated AuNRs exhibit negligible cytotoxicity and much greater cell internalization ability than CTAB-AuNRs [36]. 


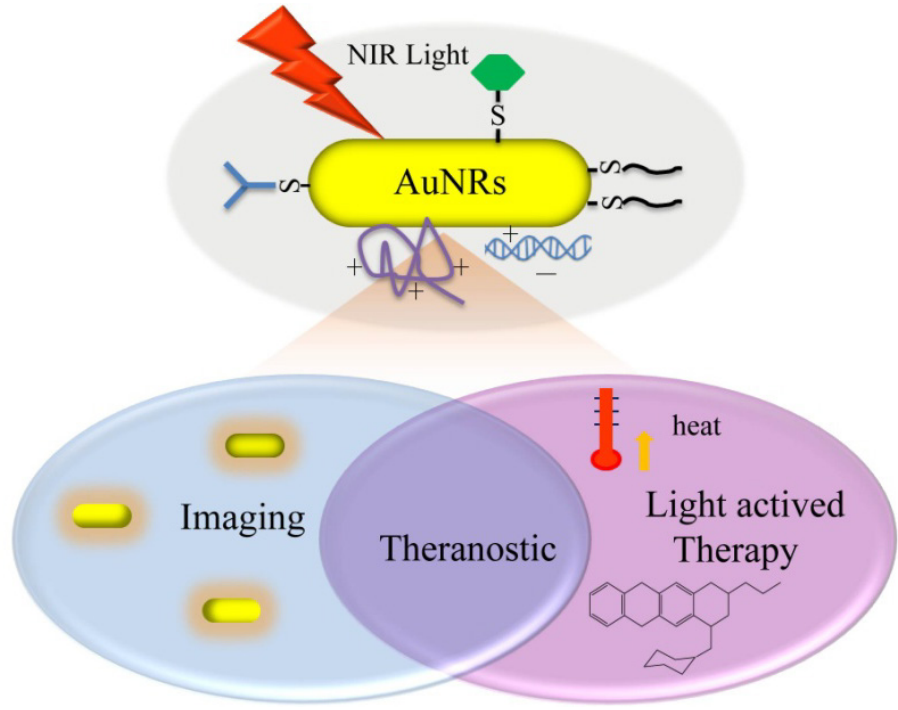

Fig I. Illustration of various light-mediated biomedical applications of AuNRs.

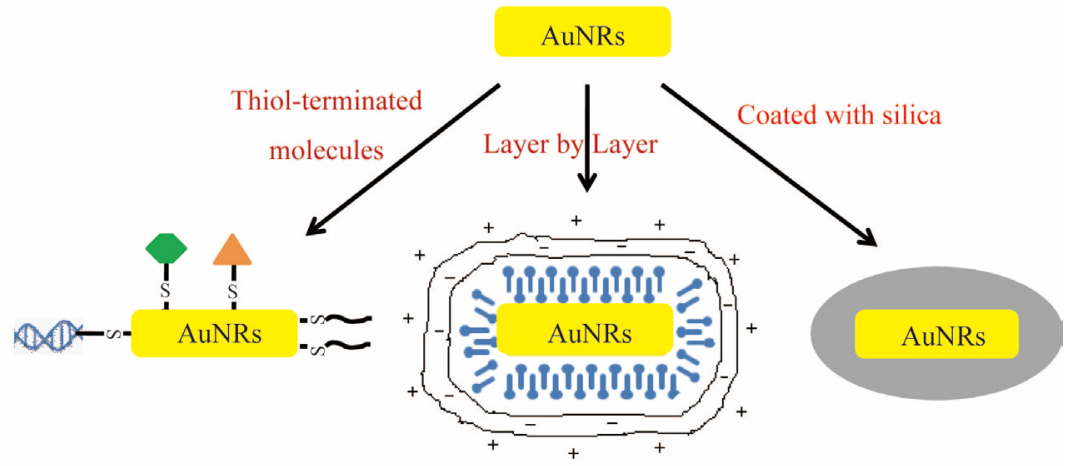

Fig 2. Three most widely used methods for surface modification and functionalization of AuNRs.

Table I. Summary of cytotoxicity of AuNRs with different surface coatings.

\begin{tabular}{|c|c|c|c|c|}
\hline Surface Coatings & $\begin{array}{l}\text { Exposure (concentra- } \\
\text { tion*, duration) }\end{array}$ & Cell Types\# & Cell Responses & Ref \\
\hline PDDAC, CTAB, PSS & $70 \mathrm{pM}, 72 \mathrm{~h}$ & MCF-7 & $\begin{array}{l}\text { uptake: PDDAC }>\text { CTAB }>\text { PSS; } \\
\text { cytotoxicity: } \text { CTAB }>\text { PSS }>\text { PDDAC }\end{array}$ & {$[36]$} \\
\hline CTAB, PEG & $200 \mu \mathrm{M}$ (Au atoms), $72 \mathrm{~h}$ & $\begin{array}{l}\text { A549, 16HBE, } \\
\text { MSC }\end{array}$ & $\begin{array}{l}\text { CTAB-AuNRs: all cell death for A549, } 75 \% \text { of cell viability to } 16 \mathrm{HBE} \text {, } \\
\text { nontoxicity to MSC; nontoxicity of PEG-AuNRs }\end{array}$ & [56] \\
\hline PSS, PEG-SH & $100 \mathrm{pM}, 24 \mathrm{~h}$ & $\begin{array}{l}\text { SKBR3, } \mathrm{CHO} \\
\text { C2C12, HL60 }\end{array}$ & $\begin{array}{l}\text { cell viability: PSS-AuNRs: } 30 \% \text {; } \\
\text { PEG-AuNRs: >90\% for SKBR3, CHO and C2C12 cells, } 20 \% \text { for HL60 } \\
\text { cells }\end{array}$ & [57] \\
\hline $\begin{array}{l}\text { PDADMAC, PSS, } \\
\text { PAH }\end{array}$ & $150 \mu \mathrm{M}(\mathrm{Au}$ atoms $), 6 \mathrm{~h}$ & $\mathrm{HeLa}$ & $\begin{array}{l}\text { PDADMAC coating: highest uptake; }>90 \% \text { of cell viability; no gene } \\
\text { overexpression }\end{array}$ & [58] \\
\hline PAA, PAH & $0.4 \mathrm{nM}$, 4days & HT-29 & cell viability: PAA-AuNRs: 90\%; PAH-AuNRs: 90\% & [59] \\
\hline PAA & $120 \mu \mathrm{g} / \mathrm{mL}, 7 \mathrm{~h}$ & SW1222 & cell viability: PAA-AuNRs: >75\% & [62] \\
\hline $\begin{array}{l}\text { thioalkyl-tri- } \\
\text { azole-peptide }\end{array}$ & $1 \mathrm{nM}, 2 \mathrm{~h}$ & HaCaT, HSC 3 & $\begin{array}{l}\text { much higher cellular uptake of peptide-AuNRs than CTAB-AuNRs; } \\
\text { more concentration in nucleus of peptide-AuNRs for cancer cells }\end{array}$ & [43] \\
\hline mesoporous silica & $122 \mu \mathrm{M}(\mathrm{Au}$ atoms $), 72 \mathrm{~h}$ & A549 & nontoxicity & [55] \\
\hline
\end{tabular}


A more recent and promising surface modification/functionalization approach is to form mesoporous silica layer around AuNRs. In 2008, Gorelikov and Matsuura reported a single-step synthesis method to coat individual CTAB-capped AuNRs with a thin layer of mesoporous silica [45]. In the coating reaction, the localized CTAB molecules on individual AuNRs functioned as the template for the three dimensional polymerization of tetraethyl orthosilicate and thus help to form the mesoporous -structured silica layer. As is well known, mesoporous silica nanoparticles are ideal drug carriers with high surface area, large pore volume, excellent biocompatibility, good chemical and thermal stability, and ease for further functionalization [46-48]. Therefore, the silica coating not only solves the CTAB toxicity and dispersion issue of AuNRs but also endows AuNRs with drug delivery and functionalization potentials, opening an exciting window for more versatile applications of AuNRs in biomedicine. So far, a few applications of mesoporous silica-coated AuNRs $\left(\mathrm{Au} @ \mathrm{SiO}_{2}\right)$ in imaging [49-52], hyperthermia therapy [53] and drug delivery [54] have been reported separately by different groups. Our group has recently developed $\mathrm{Au} @ \mathrm{SiO}_{2}$ as a light-mediated multifunctional theranostic platform for cancer treatment [55]. More details about this work will be discussed below.

\section{AuNRs as imaging agents}

In contrast to conventional organic dyes and fluorophores for NIR imaging applications, AuNRs have several pronounced advantages such as much larger absorption cross sections and more robust chemical and photophysical stabilities. The applications of AuNRs in various imaging techniques have been intensively investigated. In this review, however, we focus on those very recent developments in TPL imaging, PAT, OCT and X-ray CT, which is currently under active research.

\section{Two-photon luminescence imaging}

TPL imaging has recently gained popularity due to increased light-penetration depth, submicron spatial resolution, low background fluorescence, and reduced photodamage to living tissues. AuNRs have large two-photon absorption cross sections in the NIR region. Upon ultra-fast laser irradiation, AuNRs emit a strong TPL that can be detected under confocal conditions. The use of AuNRs for TPL imaging has been demonstrated in cultured cells, tissue phantoms, and blood vessels close to the skin surface, such as those in a mouse ear. Recently, TPL imaging was used to demonstrate effective binding of epidermal growth factor receptor (EGFR)-targeted AuNRs (an-
ti-EGFR-AuNRs) both in human epithelial carcinoma cell line cells (A431) in vitro and A431 tumors in vivo [60]. The anti-EGFR-AuNRs were observed at depths up to $100 \mu \mathrm{m}$ in the tumors. Selective targeting and accumulation of chitosan oligosaccharide-modified AuNRs were also observed in vitro via TPL imaging studies in human oral adenosquamous carcinoma cell line (CAL 27) [11], consistent with in vivo targeting studies performed via NIR laser irradiation in CAL 27 xenograft tumors (Figure 3A).

\section{Photoacoustic tomography}

PAT, an emerging imaging technique analogous to ultrasound, can offer non-invasive optical imaging at even greater depth into tissue than TPL imaging. AuNRs can also support optoacoustic properties that rely on absorption of pulsed laser to create an acoustic shockwave owing to transient superheating and thermoelastic expansion. The acoustic signal will be measured and converted into an image by a scanning transducer. Very recently, Yang et al. reported intracellular AuNRs imaging using their homemade photoacoustic microscopy. The time-dependent uptake and distribution of the AuNRs in human breast adenocarcinoma cell line were successfully monitored [61]. Jokerst et al. reported PAT imaging of mesenchymal stem cells in living mice via $\mathrm{Au} @ \mathrm{SiO}_{2}$ (Figure 3B) [17]. The authors found that the silica layer both enhanced the photoacoustic signal of AuNRs and increased uptake of the AuNRs into the cells. This $\mathrm{Au} @ \mathrm{SiO}_{2}$-mediated PAT imaging method has low background and high spatial and temporal resolutions, both of which are significant advantages over traditional cell imaging techniques like positron emission tomography and magnetic resonance imaging.

\section{Optical coherence tomography}

OCT is a relatively recent imaging modality that captures micrometer resolution, three-dimensional cellular and subcellular tissue morphology using the coherence-gated detection of scattered NIR light. AuNRs accumulated in biological tissue of interest can significantly enhance contrast due to intense optical absorption or scattering. Recently, Jung et al. reported OCT imaging of AuNRs uptake in sentinel lymph node (SLN) of mice in situ (Figure 3C) [7]. Compared to conventional scattering OCT, the AuNRs-mediated OCT system obtained 3-D images with higher resolution, based on which different time-dependent accumulation of AuNRs within several SLN structures were demonstrated. The average concentration of AuNRs within the whole SLN could be calculated by summing the OCT signal strength. 


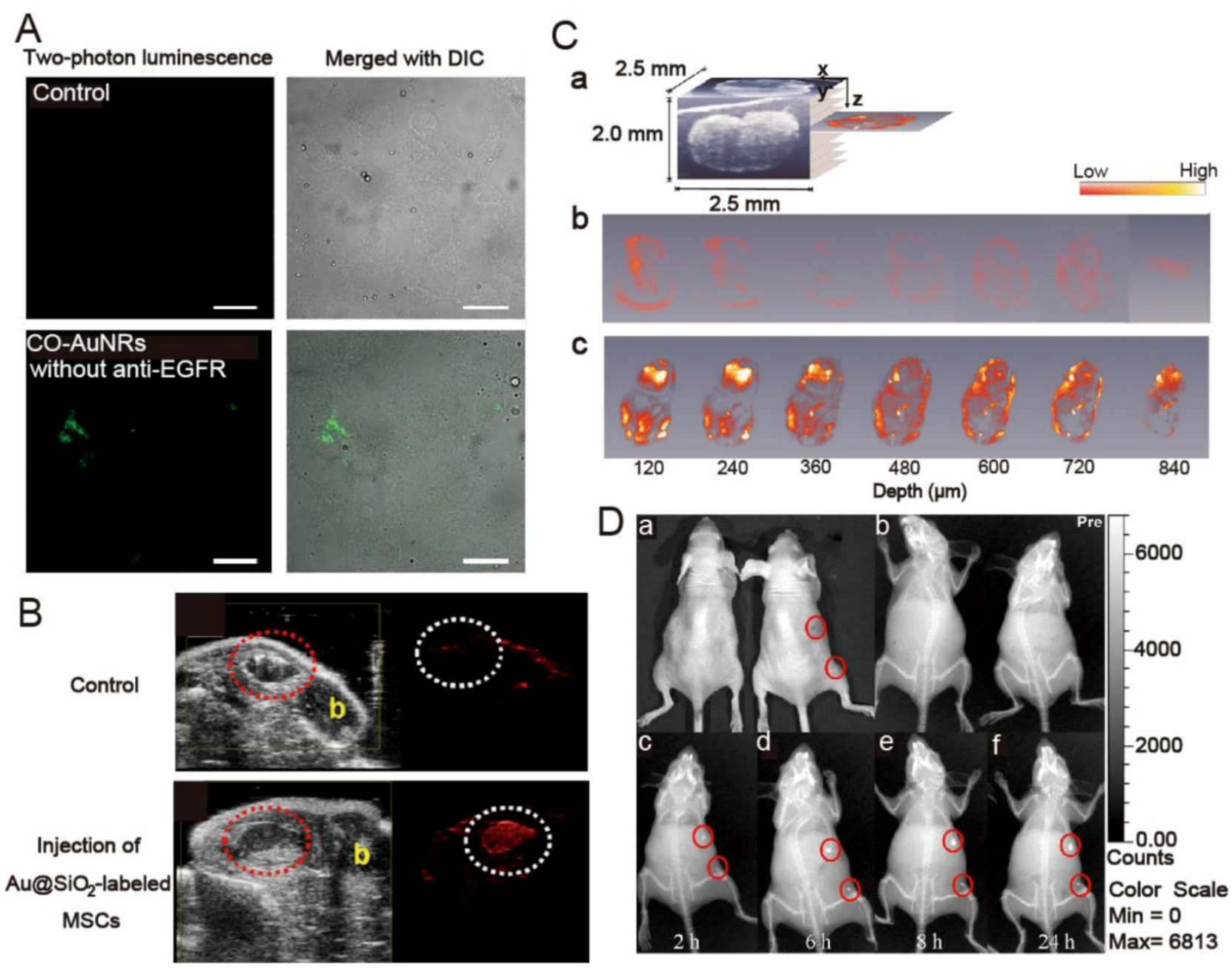

Fig 3. (A) Two-photon luminescence and merged image with differential interference contrast (DIC) of chitosan oligosaccharide-modified AuNRs with and without anti-EGFR conjugation in Cal 27cells. Cells were incubated with $0.1 \mu \mathrm{gg}$ gold nanorods for 4 hours. Scale bar, $10 \mu \mathrm{m}$. Adapted with permission from [II] (B) In vivo backscatter mode ultrasound (gray scale) and PAT (red) images of the intramuscular injection of a negative control ( $0 \mathrm{nM} \mathrm{Au@SiO}{ }_{2}$, no cells), and $800000 \mathrm{Au@SiO}$-labeled MSCs all in 50\% matrigel/PBS into hind limb muscle of an athymic mouse. The "b" in panels indicates bone and the red dashed circle highlights the injection. Adapted with permission from [17]. (C) Cross-sectional photothermal OCT images obtained at different depths below the surface by slicing the 3D data cube (shown in (a)) acquired from the SLN at the time point of (b) 12 and (c) $96 \mathrm{~h}$ after AuNRs injection. Adapted with permission from [7]. (D) In vivo X-ray imaging of mice after subcutaneous injection without and with folic acids-conjugated Au@SiO2 at different time points. (a) The photograph of mice; the X-ray images at (b) $0 \mathrm{~h}$, (c) $2 \mathrm{~h}$, (d) $6 \mathrm{~h}$, (e) at $8 \mathrm{~h}$, and (f) $24 \mathrm{~h}$. Adapted with permission from [5I].

\section{X-ray computed tomography}

As one of the most widely used diagnostic tools in hospitals today, $\mathrm{X}$-ray CT is an imaging technique based on X-ray absorption difference (absorption contrast) of the body compositions. Due to their high atomic weight and X-ray absorption coefficient, small iodinated molecules are generally used as contrast agents to improve the visibility of internal body structures in X-ray CT procedures. However, these contrast agents only allow very short time imaging due to rapid renal excretion, and may also cause renal toxicity. Recently, AuNRs have attracted much attention for the development of new CT imaging agents because gold has a higher atomic weight and X-ray absorption coefficient than iodine. It has been demonstrated that PEG-coated AuNRs (PEG-AuNRs) have a much longer circulation time than a typical iodine-based molecular contrast agent. More importantly, AuNRs conjugated with targeting ligand such as peptides or antibodies can enable visualization of disease -specific biomarkers at the molecular levels through CT procedure. Luo et al. reported indocyanine green (ICG)-loaded $\mathrm{Au} @ \mathrm{SiO}_{2}$ for the dual capability of X-ray CT and fluorescence imaging [52]. It was demonstrated that $\mathrm{Au} @ \mathrm{SiO}_{2}$ could enhance CT contrast significantly and multiplexed images can be easily obtained by using this dual mode imaging agent. In another paper, the same group also showed that X-ray imaging could be employed to monitor the tumor targeting ability of folic acid-conjugated 
$\mathrm{Au} @ \mathrm{SiO}_{2}$ during the whole blood circulation (Figure 3D) [51].

\section{AuNRs for hyperthermia therapy}

The major therapeutic application of AuNRs is to treat cancers as hyperthermia agents. Upon high power laser irradiation, AuNRs can raise the temperature of its immediate environment by hundreds of degrees due to high efficient and extremely fast photothermal conversion [1]. This localized superheating effect can be directed to eradicate the diseased tissue such as cancer, providing a noninvasive alternative to surgery. The photothermal effects of AuNRs have been well established on cultured tumor cells and tumor xenografts in mice, as well on parasitic protozoans, macrophage and bacterial pathogens. Some typical experiment conditions and therapeutic effects of AuNRs induced hyperthermia are summarized in Table 2.

Tong et al. did excellent work to study the mechanism of photo-induced cell necrosis by AuNRs [1, 21]. The authors found that photothermolysis of cells was most effective when AuNRs were adsorbed to the cell surface prior to uptake, and an influx of extracellular $\mathrm{Ca}^{2+}$ was required to produce membrane bleb formation that was in strong correlation with a gross redistribution of the cytoskeletal infrastructure. They thus attributed the cell death to the disruption of the plasma membrane which was most likely a consequence of AuNRs-mediated cavitation resulted from the photoacoustic effects (Figure $4)$.

Table 2. Selective targeting and therapeutic effects of AuNRs induced hyperthermia.

\begin{tabular}{|c|c|c|c|c|c|}
\hline $\begin{array}{l}\text { Materials with target } \\
\text { molecules }\end{array}$ & Dose & $\begin{array}{l}\text { Incubation/ } \\
\text { Circulation time }\end{array}$ & Laser Parameters & Hyperthermia Effects & Ref \\
\hline AuNR-folate & $\begin{array}{l}10^{5} \text { cells } / \mathrm{mL}, 100 \mu \mathrm{L} 0.2 \\
\mathrm{nM} \text { AuNRs }\end{array}$ & $\mathrm{N} / \mathrm{A}$ & $\begin{array}{l}\text { fs*-pulsed laser, } 765 \mathrm{~nm}, 3 \mathrm{~mW} \text {, } \\
61.5 \mathrm{~s}\end{array}$ & $\begin{array}{l}\text { membrane blebbing; cell necro- } \\
\text { sis }\end{array}$ & [21] \\
\hline AuNR-PEG & $\begin{array}{l}\text { direct injection: } 15 \mu \mathrm{L} \\
\left(\mathrm{OD}_{\lambda \max } 800=40\right) \text {; intra- } \\
\text { venous administration: } \\
100 \mu \mathrm{L}\left(\mathrm{OD}_{\lambda \max } 800=120\right)\end{array}$ & $\begin{array}{l}\text { intramural injec- } \\
\text { tion: } 2 \text { min; } \\
\text { intravenous ad- } \\
\text { ministration: } 24 \mathrm{~h}\end{array}$ & $\begin{array}{l}\mathrm{cW}^{*}, 808 \mathrm{~nm}, 6 \mathrm{~mm} \text { diameter } \\
\text { spot, } 10 \mathrm{~min} \text {. direct injection: } \\
.9-1.1 \mathrm{~W} / \mathrm{cm}^{2} ; \\
\text { intravenous administra- } \\
\text { tion:1.7-1.9W/ } \mathrm{cm}^{2}\end{array}$ & $\begin{array}{l}\text { intramural injection: resorption } \\
\text { of }>57 \% \text { (13days) } \\
\text { intravenous administration: } \\
\text { resorption of the tumors of } 25 \% \\
\text { (13days) }\end{array}$ & [20] \\
\hline A33scFv-PAA-AuNR & $\mathrm{N} / \mathrm{A}$ & $5 \mathrm{~h}$ & $\mathrm{cw}, 808 \mathrm{~nm}, 5.1 \mathrm{~W} / \mathrm{cm}^{2}, 5 \mathrm{~min}$ & $>62 \%$ cell death & [62] \\
\hline $\begin{array}{l}\text { anti-EGFR-PSS- } \\
\text { AuNRs }\end{array}$ & $\begin{array}{l}10^{6} \text { cells, } 6.023 \times 10^{11} \\
\text { AuNRs }\end{array}$ & $\mathrm{N} / \mathrm{A}$ & $\mathrm{cw}, 650 \mathrm{~nm}, 0.3 \mathrm{~mW} / \mathrm{cm}^{2}, 3 \mathrm{~min}$ & $\begin{array}{l}92 \% \text { mortality of the carcinoma } \\
\text { cells; unclear boundary, mem- } \\
\text { branous vesicles and fragmen- } \\
\text { tation of cells }\end{array}$ & [63] \\
\hline
\end{tabular}

RGD-AuNRs in vitro: $100 \mu \mathrm{g} / \mathrm{mL} \quad$ in vivo: $6 \mathrm{~h}$ AuNRs; in vivo: $200 \mu \mathrm{g}$, intravenous administration

in vitro: $808 \mathrm{~nm}, 4-20 \mathrm{~W} / \mathrm{cm}^{2}$, $4 \mathrm{~min}$; in vivo: $808 \mathrm{~nm}$, $24 \mathrm{~W} / \mathrm{cm}^{2}, 5 \mathrm{~min}$, irradiation for four times per month, once in four sample mice from test every week all cancer cells were killed within the laser spots; disappearance of tumors implanted group of ten

\footnotetext{
*: A laser can be classified as operating in either continuous or pulsed mode, depending on whether the power output is continuous over time or whether its output takes the form of pulses of light on one or another time scale. CW is the abbreviation of continuous wave. fs-pulsed laser means that a laser can generate pulses of light as short as a few femtoseconds $\left(10^{-15} \mathrm{~s}\right)$.
}
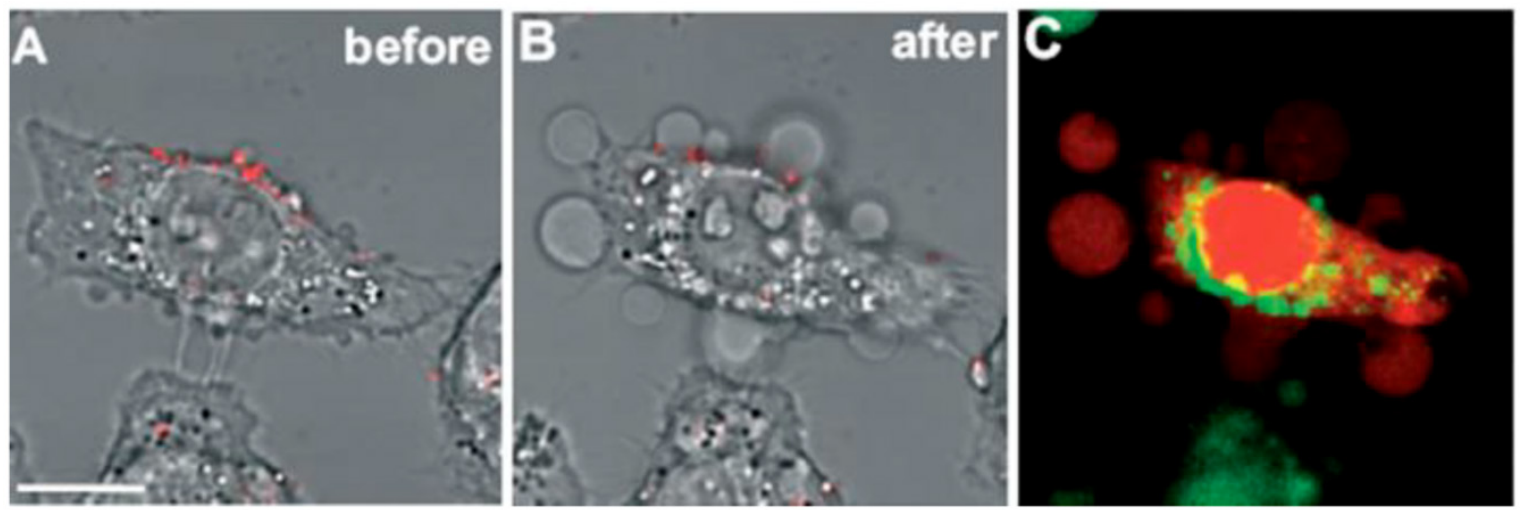

Fig 4. Membrane blebbing is induced by $\mathrm{Ca}^{2+}$ influx during AuNRs-mediated photothermolysis. (A,B) Cells with membrane-bound AuNRs (red) in PBS containing $0.9 \mathrm{mM} \mathrm{Ca}^{2+}$ exhibited blebbing after exposure to fs-pulsed laser irradiation at $3 \mathrm{~mW}$ for $61.5 \mathrm{~s}$. (C) Incubation with $2.5 \mu \mathrm{M}$ EB (red) and $2 \mu \mathrm{M}$ Oregon Green 488 for 20 min indicated a compromise in membrane integrity and an elevation in intracellular $\mathrm{Ca}^{2+}$, respectively. Scale bar $=10 \mu \mathrm{m}$. Adapted with permission from [2I]. 
Dickerson et al. reported the potential of using AuNRs for in vivo photothermal therapy by using PEG-AuNRs [20]. The nanoparticles were delivered to subcutaneous squamous cell carcinoma xenografts grown in nude (nu/nu) mice by both direct and intravenous injection. Specific tumor growth suppression from both direct and intravenous NIR laser induced photothermal therapy treatments were observed with no statistically significant differences. Obvious resorption of the tumors indicated that the potential curative applications of AuNRs-mediated photothermal therapy in pre-clinical settings.

AuNRs-mediated hyperthermia is inherently localized, but specifically targeted AuNRs are expected to be much more effective at avoiding photothermal ablation of healthy cells which may result from a nonspecific uptake of AuNRs. Kirui et al. prepared poly(acrylic acid) (PAA)-coated AuNRs with an antibody (A33scFv, a single-chain antibody) conjugated for selective colorectal carcinoma targeting [62]. Selective targeting and uptake of AuNRs in antigen expressing cells compared to antigen free cells were observed by using fluorescence microscopy. Upon irradiation with NIR laser for $5 \mathrm{~min},>62 \%$ cells were killed through AuNRs-mediated photothermal therapy, while the viability of HT29 cells remained almost unchanged, indicating that the targeted A33-AuNRs conjugates are potent photothermal absorbers in cells that express A33 antigen. Rejiya et al. demonstrated the anti-cancer potential of PSS-coated AuNRs with EGFR antibody conjugated (anti-EGFR-AuNRs) [63]. The efficient uptake of anti-EGFR-AuNRs by A431 cells was confirmed by inductively coupled plasma atomic emission spectroscopy (ICP-AES) and immunofluorescence studies. Results show that about $87.5 \%$ of anti-EGFR conjugated gold nanorods was extensively took up by cell within $3 \mathrm{~h}$ when compared to unconjugated gold nanorods i.e. $64 \%$ in $3 \mathrm{~h}$. The efficacy of the anti-EGFR- AuNRs coupled with laser treatment was evident with $92 \%$ mortality of the carcinoma cells, while cells given unconjugated AuNRs and laser treatment exhibited only $9 \%$ cell death. Flow cytometry analysis showed that anti-EGFR-AuNRs could selectively destruct the cancer cells and induce its apoptosis through ROS-mediated mitochondrial pathway under low power laser exposure.

The in vivo tumor targeting and photothermal therapy was demonstrated by $\mathrm{Li}$ et al. using RGD-conjugated dendrimer-modified AuNRs (RGD-AuNRs) [64]. It was demonstrated that RGD-AuNRs could specifically target $\alpha_{v} \beta_{3}$ integrin overexpressed tumor cells both in vitro and in vivo and thus selective destructive effects on solid tumors and even complete tumor removal under NIR laser irra- diation were achieved. Results show that $17 \%$ of the RGD-AuNRs accumulated in local tumor tissues at $6 \mathrm{~h}$ after injection and only $7 \%$ of RGD free AuNRs reached the tumor tissues at the same time, which proved the active targeting effects of RGD-AuNRs. Therefore, the RGD-AuNRs based targeting photothermal therapy hold the potential to extend to various tumors with overexpressed $\alpha_{v} \beta_{3}$ integrins.

Although the targeting on cancer cells is generally achieved by adding active ligands for specific recognition of membrane biomarkers, Zhou at al. reported zwitterionic phosphorylcholine (PC) as a new ligand for AuNRs stabilization with unexpected specific cancer targeting abilities [65]. It was demonstrated that the conjugation of PC onto AuNRs brought good dispersion stability and low cytotoxicity. Cell internalization studies by ICP-AES, transmission electron microscopy (TEM) and UV-Vis spectroscopy all supported that PC-coated AuNRs could selectively enhance cell uptake within cancer cells over related normal ones. The ICP-AES results also reflected that the number of PC-coated AuNRs within each cell surpassed more than two times the number of PEG-coated AuNRs. Selective accumulation made them able to kill cancer cells at a low laser energy which did not harm the neighboring normal ones.

\section{AuNRs as drug and gene delivery vehi- cles}

On-demand drug release can be triggered and mediated by the unique environments of tissues or external stimuli. Some excellent delivery systems responding to the slightly acidic $\mathrm{pH}$ or specific protease activity of tumor tissues have been successfully applied in tumor therapy [46, 66-67]. As the external stimulations, light, magnetic fields, ultrasound, electricity and heat is the most commonly used switch/mediator for release control [68]. The use of light as a remote-activation mechanism for drug delivery has received increased attention due to its advantages in highly flexible control of dosage and timing [24,69]. When AuNRs are used as drug delivery vehicles, that is, drugs are physically absorbed or chemical conjugated onto the surface of AuNRs, the dissipation of absorbed light energy as heat can help to release drugs actively. In other words, light-controlled drug delivery can be achieved through AuNRs mediated photothermal effects. For these reasons, AuNRs have been applied as drug delivery vehicles responding to NIR light irradiation.

DNA and RNA are the earliest "drugs" delivered by AuNRs partly because they can be easily absorbed or chemically conjugated onto the surface of 
AuNRs and are able to keep their functions after being released. In 2005, Niidome and coworkers reported a Phosphatidylcholine (PC) coated AuNRs with immobilized plasmid DNA, release of which was induced by pulsed NIR laser irradiation [70]. The authors attributed the reason of the release to the surface area decrease resulted from morphological changes of AuNRs (reshaping and fusion) upon laser irradiation. Later, the same group reported AuNRs-embedded $\mathrm{N}$-isopropylacrylamide hydrogels, which have thermo-sensitive properties [71]. Obvious phase transition behavior induced by NIR laser irradiation through the photothermal conversion characteristics was observed under optical microscopy. When a gel containing a model drug (rhodamine-labeled dextran) was irradiated, the rapid irradiation-point specific release of the drug was observed under fluorescence microscope. More recently, they reported a controlled-release system mediated by a photothermal effect induced retro Diels-Alder Reaction, which is known to proceed at $90^{\circ} \mathrm{C}$ [72]. Hamad-Schifferli and co-workers demonstrated the ability to load and selectively release two different DNA oligonucleotides from a mixture of two different AuNRs by using NIR laser corresponding to their SPR maximum wavelengths [23]. This work suggests AuNRs' potential applications in delivering more than one drugs sequentially for combination therapy (Figure 5).

Chakravarthy and coworkers employed AuNRs to deliver an innate immune activator (ssRNA) against type A influenza virus [73]. They prepared nanoplexes by conjugating the ssRNA onto AuNRs (nanoplexes) through electrostatic interaction and evaluated their efficacy in human respiratory bronchial epithelial cells infected with type A influenza virus. The intracellular delivery of the nanoplexes could be easily observed from the strong orange-red light scattering of AuNRs using dark-field microscope. Based on TEM observations, the author postulated that the nanoplexes might be taken up by classical pinocytotic mechanisms of uptake. RT-PCR and western plot results showed that the nanoplex activated the retinoic acid-inducible gene I (RIG-I) pathogen recognition pathway, resulting in increased expression of IFN- $\beta$ and other IFN-stimulated genes (ISGs) and this increase in type I IFN and ISGs resulted in a decrease in the replication of H1N1 influenza viruses (Figure 6).

Recently, our group demonstrated that PDDACand PEI-coated AuNRs could be used as DNA vaccine adjuvant for HIV treatment, that is, HIV-1 Env plasmid DNA was delivered into host cells by these two surface-modified AuNRs for enhanced immunity [48]. Our in vitro results demonstrated that PDDAC- and
PEI-coated AuNRs had good transfection capability. Both cellular and humoral immunity were enhanced significantly when mice were immunized with these two DNA-conjugated AuNRs. For the PDDAC group, the type of immune response was Th2-biased. Based on the findings that both the two AuNRs could promote the maturation of dendritic cells (DCs) while CTAB-AuNRs could not, we postulated that DC maturation might be the mechanism for the positive effects of PDDAC- and PEI-coated AuNRs as vaccine adjuvant/delivery systems. To the best of our knowledge, this is the first report on the application of AuNRs as DNA vaccine adjuvants (Figure 7). These findings will shed light on the rational design of low-toxic nanomaterials as a versatile platform for vaccine nanoadjuvants/delivery systems.

Min et al. employed AuNRs as drug delivery vehicles for a small molecular weight drug, cisplatin [74]. The drug delivery system was constructed by tethering a $\mathrm{Pt}$ (IV) prodrug to amine functionalized PEG-AuNRs. This delivery system is stable under physiological conditions with significantly higher cytotoxicity compared with free cisplatin on different types of cancer cells. This result provides an efficient approach to improve the efficacy of platinum drugs in cancer treatment.

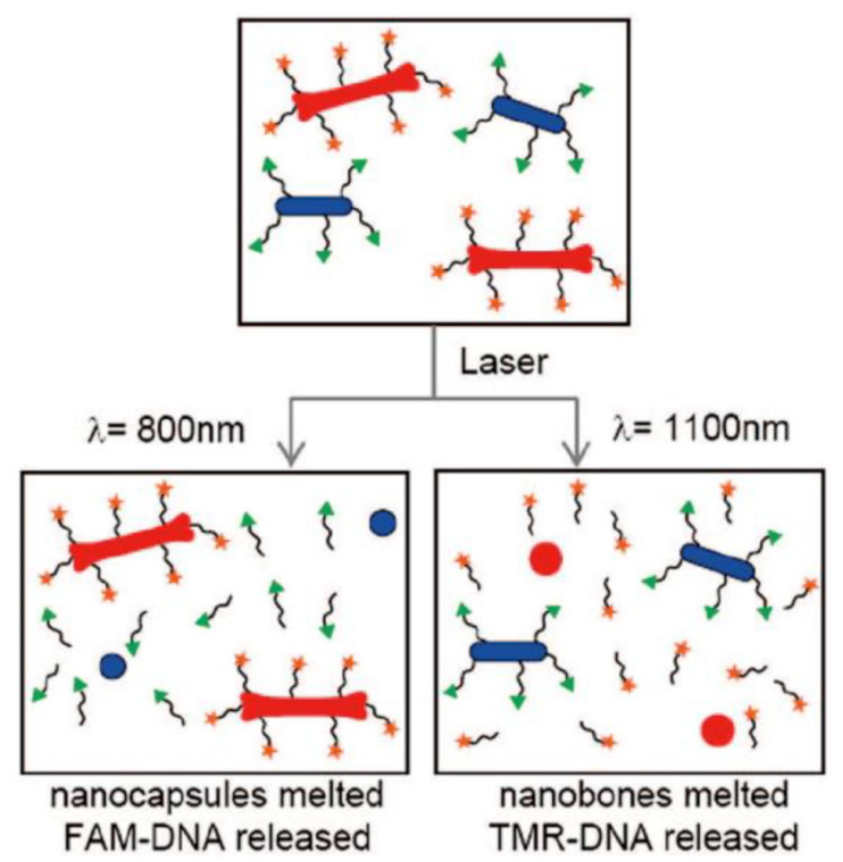

Fig 5. Overview of selective release. Laser irradiation of DNA-conjugated nanocapsules (blue ovals) and nanobones (red bones) are exposed to 800 irradiation (left), which melts the nanocapsules and selectively releases the conjugated DNA (labeled by FAM (green triangles)). Exposure to 1100 irradiation (right) melts the nanobones, selectively releasing the conjugated DNA (labeled by TMR (orange stars)) [23]. 

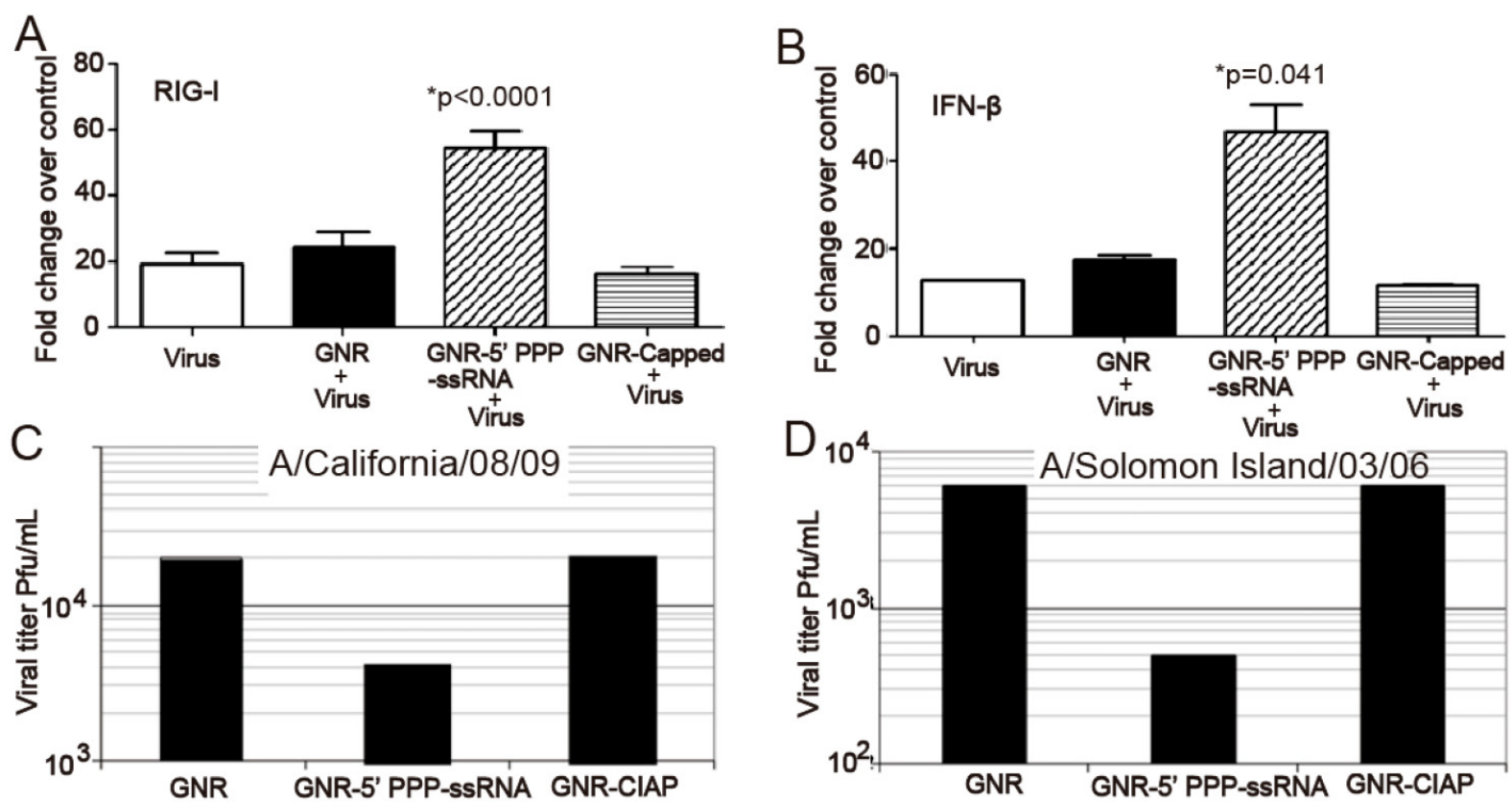

Fig 6. GNR-5'PPP-ssRNA enhances IFN- $\beta$ and RIG-I expression and inhibits replication of 2009 pandemic HINI influenza viruses and Solomon Islands seasonal flu strain. A459 cells $\left(3.5 \times 10^{5}\right.$ cells/well) in a six-well tissue culture plate were mock transfected or transfected with $3 \mu \mathrm{g}$ of RNAs complexed with $2.5 \mu \mathrm{g}$ of GNRs per well for $48 \mathrm{~h}$ and then infected with $\mathrm{A} / \mathrm{California} / 08 / 09$ or $\mathrm{A} / \mathrm{Solomon}$ Islands/03/06 at an MOI of I. Lysates to determine mRNA levels by qRT-PCR (A and $B$ ). The viral titers were determined from the supernatants collected $24 \mathrm{~h}$ later $(\mathrm{C}$ and $\mathrm{D})$ [73]. (GNRs: gold nanorods; CIAP: calf intestinal alkaline phosphatase)
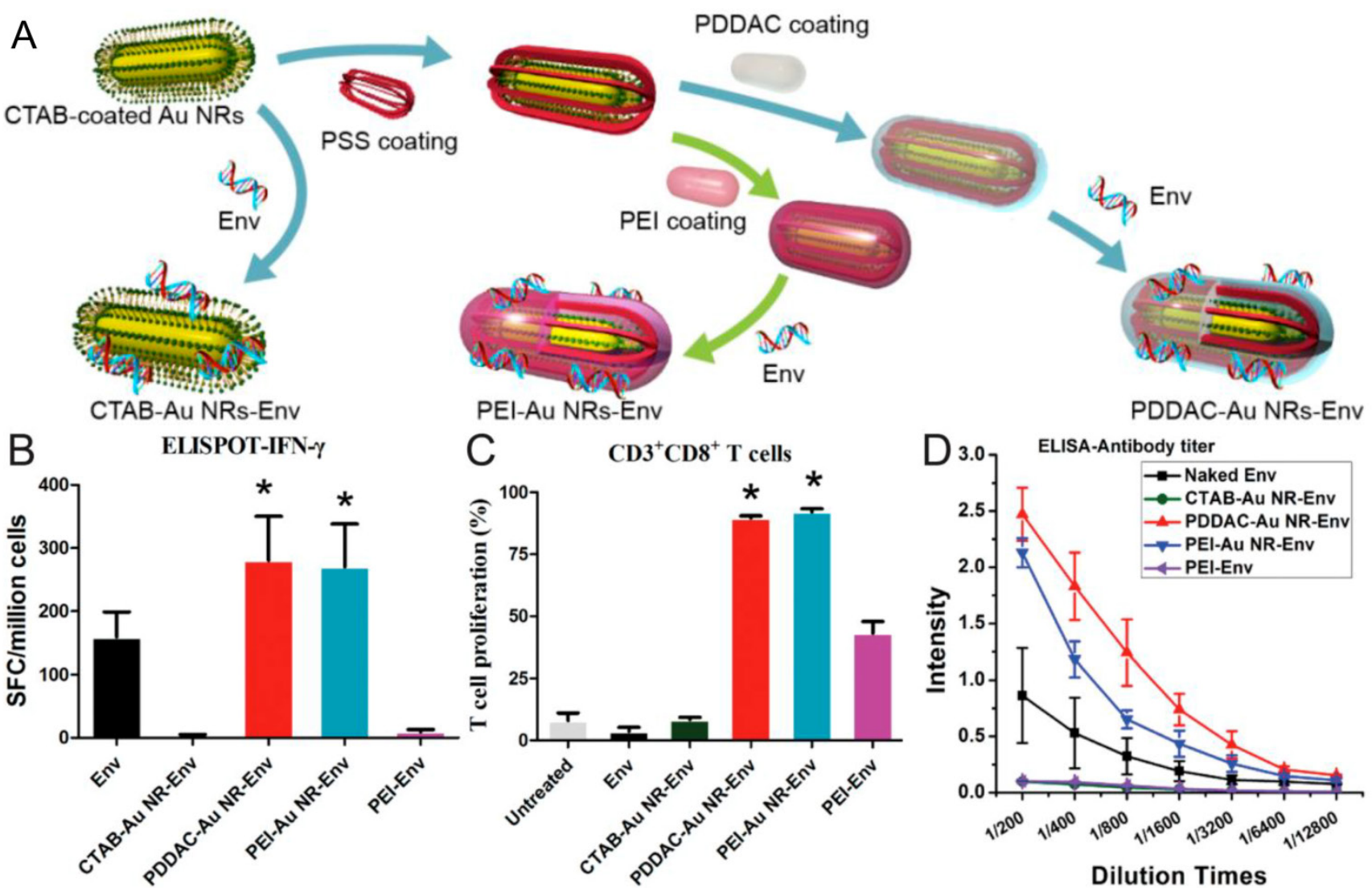

Dilution Times

Fig 7. The AuNRs-HIV Env plasmid complex formed and the effects of AuNRs on the immune response and dendritic cell maturation. (A) AuNRs with different surface coatings mixed with Env plasmid. (B) IFN-y analyzed by ELISPOT. (C) CD3 ${ }^{+} \mathrm{CD} 8^{+} \mathrm{T}$ cells proliferation. (D) The Env 69 specific antibody titer measurement. Adapted with permission from [48]. 
Table 3. Typical combined applications of AuNRs.

\begin{tabular}{|c|c|c|c|c|c|}
\hline Surface Group & Targeting Ligand & Imaging Modalities & Drug Delivered & Therapeutic Characteristics & Ref \\
\hline PSS & EGFR antibodies & $\begin{array}{l}\text { light scattering of } \\
\text { AuNRs }\end{array}$ & none & $\begin{array}{l}\text { half laser energy needed for malignant cells to be } \\
\text { photothermally destroyed than nonmalignant cells }\end{array}$ & [75] \\
\hline PEG & folic acids & TPL & none & extensive cell membrane blebbing by hyperthermia & [76] \\
\hline PEG & Deltorphin & AuNRs luminescence & none & $\begin{array}{l}\text { selective destruction of receptor-expressing cells while } \\
\text { sparing receptor-free cells }\end{array}$ & [41] \\
\hline PSMA & none & ICG luminescence & none & $\begin{array}{l}\text { hyperthermia combined with PDT with improved } \\
\text { photo-destruction efficacy }\end{array}$ & [79] \\
\hline $\begin{array}{l}\text { Cy5.5 } \\
\text {-peptide }\end{array}$ & $\begin{array}{l}\text { MMP substrate } \\
\text { peptide }\end{array}$ & Cy5.5 fluorescence & none & $\begin{array}{l}\text { simultaneous in vivo diagnosis and photothermal } \\
\text { therapy }\end{array}$ & [78] \\
\hline PEG & CET & $\begin{array}{l}\text { NIR absorption of } \\
\text { AuNRs }\end{array}$ & none & $\begin{array}{l}\text { extensive pyknosis and cell vacuolization in tumor } \\
\text { tissue by hyperthermia }\end{array}$ & [77] \\
\hline PSS, PDDAC & none & $\begin{array}{l}\text { light scattering of } \\
\text { AuNRs }\end{array}$ & siRNA & $\begin{array}{l}\text { significant impact on suppression of GAPDH gene } \\
\text { expression }(70 \% \text { gene silencing, }>10 \text { days } \\
\text { post-injection) }\end{array}$ & [80] \\
\hline PDDAC & none & TEM & cisplatin & $\begin{array}{l}\text { with AuNRs heating, drug dosage lowered to roughly } \\
33 \% \text { of the unheated amount to achieve comparable } \\
\text { cytotoxicity }\end{array}$ & [81] \\
\hline PEG, dDNA & folate & $\begin{array}{l}\text { Cy3 } \\
\text { luminescence }\end{array}$ & DOX & $\begin{array}{l}\text { selective drug delivery to target cells, effective inhibi- } \\
\text { tion of tumor growth through thermo-chemotherapy }\end{array}$ & [82] \\
\hline $\begin{array}{l}\text { mesoporous } \\
\text { silica }\end{array}$ & none & TPL & DOX & $\begin{array}{l}\text { two therapeutic modes of chemotherapy and hyper- } \\
\text { thermia, switchable by changing laser power density }\end{array}$ & [55] \\
\hline
\end{tabular}

\section{Combined applications}

There is currently considerable effort to develop theranostic nanoscale systems for more effective treatment of cancer. The unique physicochemical properties endow nanomaterials with great potential to integrate imaging diagnosis and therapeutic treatment into a single nanoplatform for combined cancer treatments such as imaging -guided therapy and therapeutic monitoring following treatments. Development of such multifunctional theranostic systems with individual functions acting in a coordinated way is critical to optimize therapeutic efficacy and safety of therapeutic regimes, and could provide more opportunities for on-demand therapy and pave the road toward personalized medicine.

Although AuNRs are inherently capable of various types of imaging and therapeutic functionalities, more functional modalities such as conventional fluorescence imaging, active targeting, and controlled drug release can be readily added due to various robust surface modification methods available. This provides great opportunities for the combination application of AuNRs in biomedicine. In this section, we review such combined applications for theranostic purpose such as image-guided therapy. Some recent typical combined applications of AuNRs are summarized in Table 3.

\section{Combination of imaging and hyperthermia therapy}

In 2006, El-Sayed and coworkers first developed
AuNRs as reagents for simultaneous molecular imaging and photothermal cancer therapy [75]. They prepared anti-EGFR -AuNRs and applied them to treat malignant oral epithelial cell lines. Using dark field imaging based on light scattering of AuNRs, the malignant cells were clearly visualized and diagnosed from the nonmalignant cells. Based on the extinction spectra of AuNRs in single cells, anti-EGF-AuNRs bound specifically to the surface of the malignant type cells with a much higher affinity due to the overexpressed EGFR on the membrane of the malignant cells. As a result of preferable binding of anti-EGFR -AuNRs, malignant cells required about half the laser energy to be photothermally destroyed than the nonmalignant cells upon exposure to continuous NIR laser.

Since the application in both imaging and hyperthermia therapy doesn't require AuNRs to be further functionalized, imaging-guided hyperthermia therapy has been the most investigated combination among all possible combinations of various applications of AuNRs. Targeting molecules are often conjugated to AuNRs for specific cancer detection and therapy. Huff et al. compared the cell internalization behavior of CTAB-AuNRs and FA-AuNRs using TPL imaging [76]. The former was found to be internalized in to KB cells within hours while the latter accumulated on the cell surface over the same time interval. In either case, AuNRs-mediated heating could produce severe blebbing in cell membranes and render them permeable to chemical regents. Black et al. attached deltorphin, a high-affinity ligand for delta opioid re- 
ceptor ( $\delta \mathrm{OR})$ to AuNRs through a thiol-terminated PEG linker and demonstrated selective imaging and destruction of receptor-expressing cells while sparing those cells that did not express the receptor in a mixed population of cells [39]. Choi et al. conjugated cetuximab (CET), an epithelial cancer cells targeting molecules, to PEG-AuNRs (CET-AuNRs) and accessed their targeting, imaging and hyperthermia therapy behavior [77]. ICP-AES results showed that CET-AuNRs preferably to A431 cells over MCF-7 cells. The cell internalization of CET-AuNRs in A431 cells was clearly observed by TEM. In vivo NIR absorption imaging results showed that CET-AuNRs accumulated in the tumor region after intravenously injected while CET free AuNRs did not, consistent with the results obtained by ICP-AES. After NIR laser irradiation, histological analysis of excised tumor tis- sue showed that CET-AuNRs-treated tumors exhibited severe cellular damage compared to non-treated controls.

Yi et al. designed and prepared a NIR fluorescent dye coupled AuNRs through a peptide linker, which is known to be degraded by matrix metalloprotease (MMP) [78]. MMP is a family of zinc-dependent proteins and the production of MMPs are distinctly involved in cancer metabolism. For the quenching effect of AuNRs, NIR fluorescence was quenched until the substrate was degraded by MMP enzymes which were secreted by cancer cells. By the recovery of quenched fluorescence, the authors determined the expression of MMP and cancer progress as well as performed hyperthermia cancer therapy simultaneously based on photothermal effects of AuNRs (Figure 8).

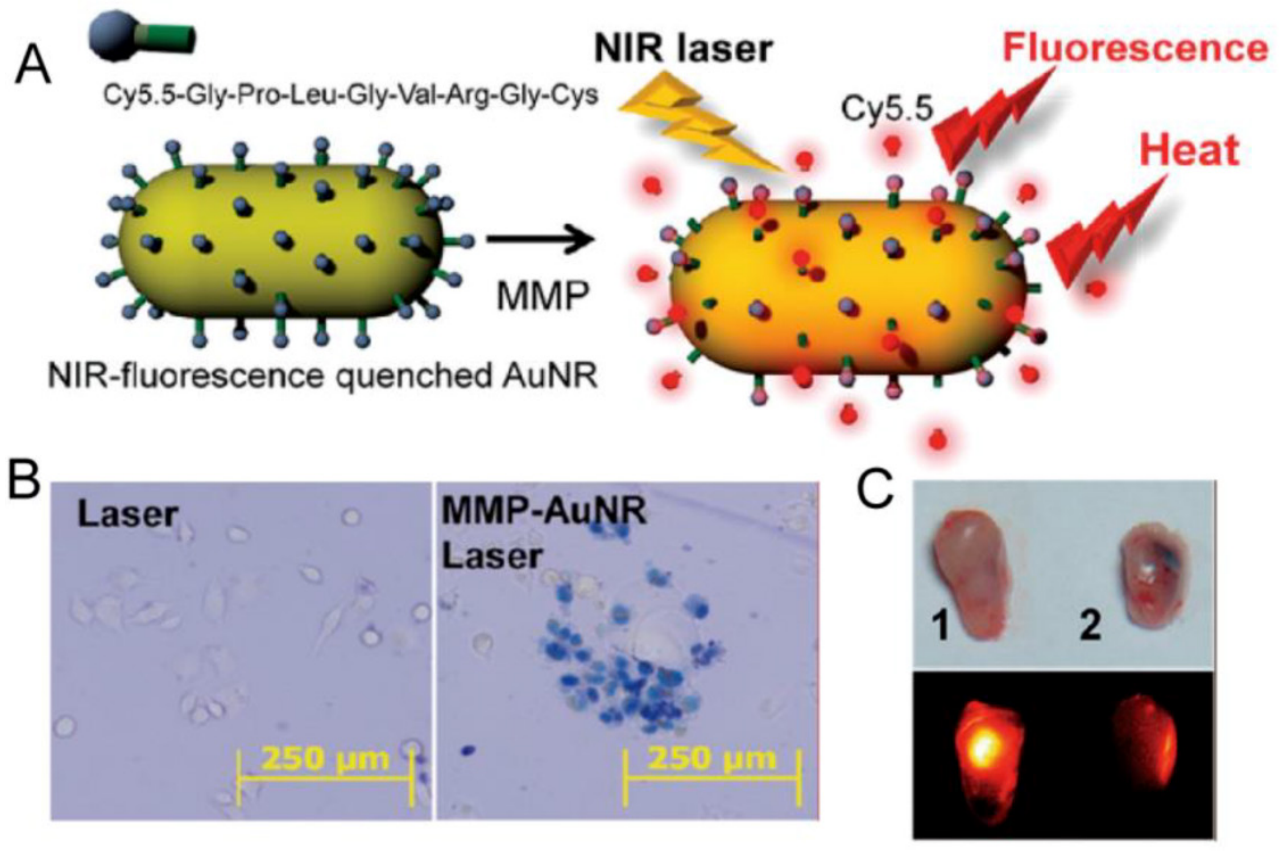

D 1: MMP-AuNR, 2: MMP-AuNR/(+) inhibitor
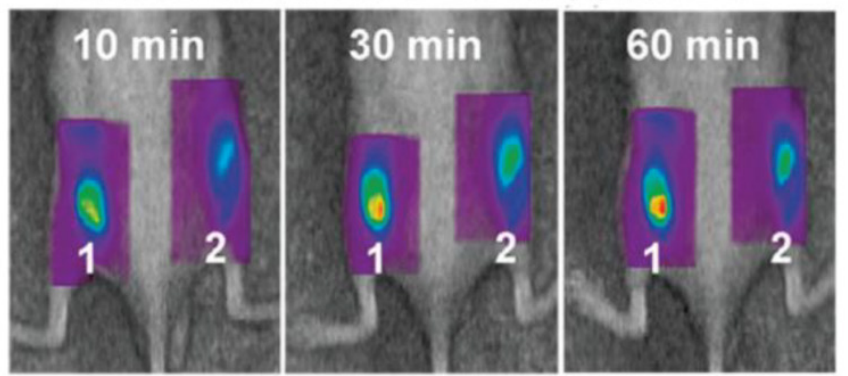

Fig 8. (A) Schematic Representation of Synthesis of MMP-AuNRs for Simultaneous Imaging and Photothermal Therapy. (B) Microscopic images of HeLa cell after staining with trypan blue at different treatment conditions. (C) Optical and NIR fluorescent images of excised tumor after injection of MMP-AuNRs without and with MMP-2 inhibitor. (D) NIR fluorescent tomographic images of SCC-7 tumor-bearing mice after intratumoral injection of the MMP-AuNRs probe without (I) and with (2) inhibitor. Adapted with permission from [78]. 
Kuo et al. coated AuNRs with poly(styrenealtmaleicacid) (PSMA) and indocyanine green (ICG), a hydrophilic and anionic photosensitizer, in sequence via electrostatic interaction, and developed them as both photodynamic therapy (PDT) and hyperthermia agents [79]. It was demonstrated that combined PDT and hyperthermia could more efficiently extinguish cancer cells than PDT or hyperthermia treatment alone, and the system could also serve as an effective bio-imaging probe in the NIR region based on the fluorescence of ICG (Figure 9).

\section{Combination of imaging and drug delivery}

Wang et al. developed hollow and rattle-type nanocapsules composed of AuNPs as cores and fluorescent mesoporous silica shells (rattle- $\mathrm{Au} @ \mathrm{SiO}_{2}$ ) for simultaneous imaging and drug delivery [54]. The authors coated AuNRs with mesoporous silica together with a fluorescent imaging agent, rhodamine B isothiocyanate (RITC) and then etched the AuNRs cores to spindle-shaped Au nanoparticle via a small amount of aqua regia. A well-known chemotherapy drug, doxorubicin (DOX) was loaded into the hollow interiors with high loading efficiency. Intracellular distribution of rattle-Au@SiO 2 was visualized through the fluorescence of RITC. Intracellular drug release with comparable cytotoxic effect to free drug was also demonstrated (Figure 10).

Bonoiu et al. reported siRNA carried AuNRs for in vivo gene silencing in the rat hippocampus [80]. The authors modified the surface of AuNRs using the layer-by-layer method and absorbed a fluorescent labeled siRNA against glyceraldehyde 3-phosphate dehydrogenase (GAPDH). The AuNRs-siRNA nanoplex was stereotaxically injected into the CA1 region of the hippocampus in Sprague-Dawley rats. In vivo cellular localization of nanoplexes was analyzed by immunofluorescent labeling. The nanoplexes appeared to remain localized into the CA1 region, with little diffusion to adjacent regions. Quantitative real-time PCR results showed significant suppression of GAPDH gene expression in the CA1 region after the nanoplexes were administered.

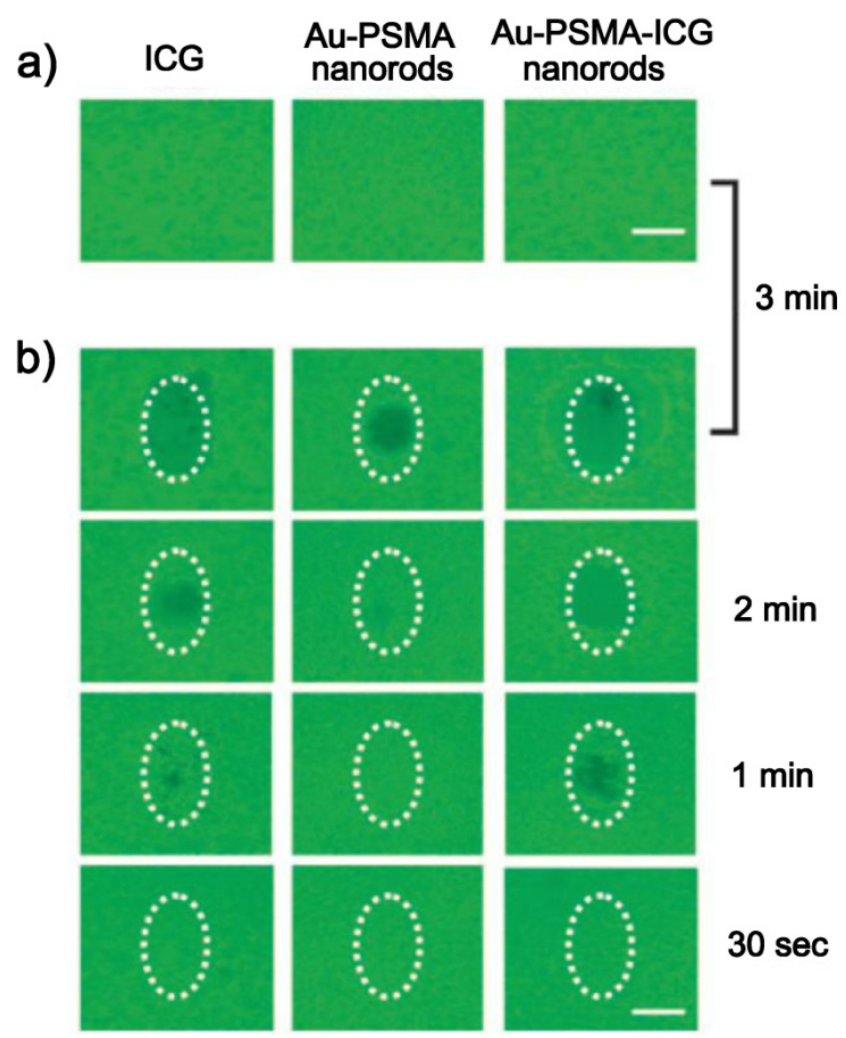

Fig 9. Photodestruction of A549 malignant cells shown by fluorescence. ICG, Au-PSMA nanorods, and Au-PSMA-ICG nanorods a) without and b) with conjugated $A b_{E G F R}$-treated $A 549$ cells, and irradiated by an NIR laser $(808 \mathrm{~nm})$ at $22.5 \mathrm{~W} \mathrm{~cm}^{-2}$ power density. The dotted circles indicate the laser beam area. The cells were stained with calcein AM and incubated for $2 \mathrm{~h}$ in the dark after irradiation; live cells exhibited green fluorescence. Scale bar: I mm. Adapted with permission from [79].

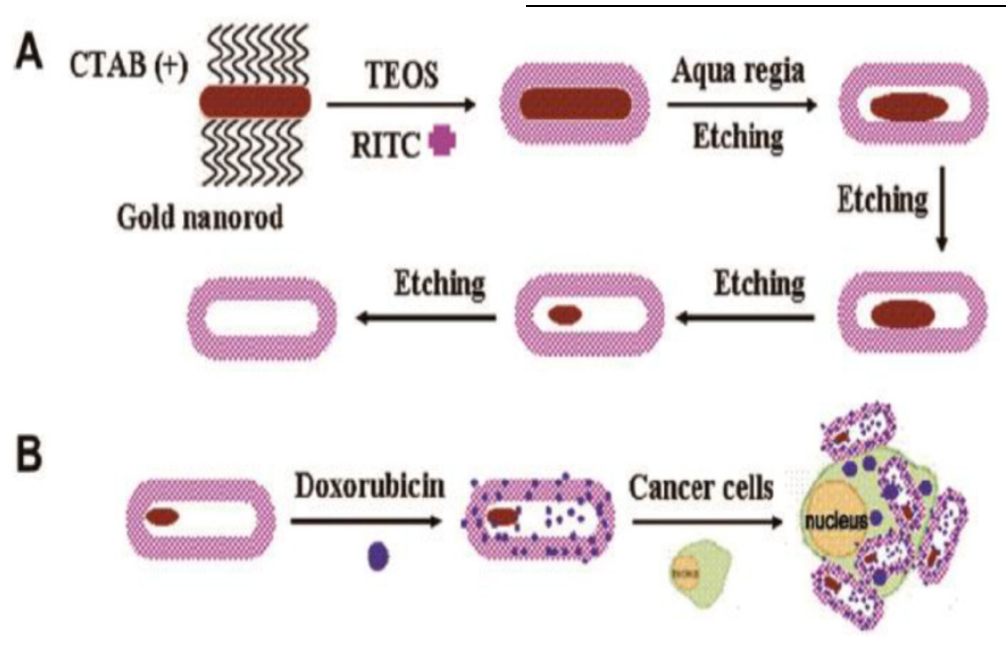

Fig 10. (A) Schematic illustration of the synthetic procedure for RITC-labeled hollow/rattle-type Au@ $\mathrm{SiO}_{2}$ nanocapsules and (B) application in fluorescent drug delivery for HepG-2 cancer cells. (RITC, rhodamine B isothiocyanate). Adapted with permission from [54]. 
Very recently, Xiao et al. developed a PEG-AuNRs with DOX conjugated through a $\mathrm{pH}$-sensitive hydrazone bond [40]. Targeting ligand cRGD, and positron emission tomography (PET) imaging agent ${ }^{64} \mathrm{Cu}$-chelators were tethered to the distal ends of the PEG arms. Cellular uptake and cytotoxicity studies demonstrated that the cRGD-conjugated AuNRs showed a higher cellular uptake and thus a more potent cytotoxicity in $\alpha_{v} \beta_{3}$ integrin overexpressing cancer cells when compared to the cRGD-free AuNRs nanocarriers. However, according to in vivo PET imaging and biodistribution studies, the two nanocarriers had similar in vivo biodistribution, which suggested that cRGD conjugating didn't confer a significant advantage for in vivo tumor uptake.

\section{Combination of hyperthermia and drug deliv- ery}

The combination of heat and chemotherapeutic agents is a very promising approach to optimize the efficacy of cancer treatments because of a synergistic interaction between thermal therapy and certain chemotherapeutics. Hauck and coworkers reported one of the first instances in which nanoparticle heating has been combined with chemotherapy. PDDAC-coated AuNRs and cisplatin, a chemotherapeutic drug which has a known synergy, was applied separately to cultured mammalian cells. They found that combining AuNRs heating with cisplatin lowers the cytotoxic drug dosage requirements to roughly $33 \%$ of the unheated amount to achieve comparable cytotoxicity, which has important implications to the dose-dependent renal side effects of cisplatin [81].

Very recently, Xiao and co-workers have developed a targeted NIR-responsive AuNRs-based delivery platform by a simple DNA self-assembly process. Thiolated DNA was tethered to AuNRs together with its complimentary strand. The DNA strands, which consist of sequential CG base pairs, provide loading sites for Dox. AuNRs serve as the model NIR light-to-heat transducer for cancer thermotherapy and for denaturing the DNA double helix upon NIR irradiation, leading to the triggered release of loaded drugs at target site for chemotherapy. The in vitro and in vivo results demonstrate that this platform selectively delivers anti-cancer drugs to target cells, releases them upon NIR irradiation, and effectively inhibits tumor growth through thermo-chemotherapy [82].

\section{Combination of imaging, hyperthermia and drug delivery}

Although they have been demonstrated to be promising imaging and therapeutic agents, AuNRs only have limited specific surface area and are not appropriate to be used as an efficient carrier for drug delivery. To solve this problem, our group has recently evaluated the potential applications of $\mathrm{Au} @ \mathrm{SiO}_{2}$ in imaging, chemotherapeutics, and hyperthermia cancer therapy [55]. In this work, TPL imaging was employed to visualize the intracellular co-localization of $\mathrm{Au} @ \mathrm{SiO}_{2}$ with DOX and some cellular compartments. NIR laser irradiation at a low intensity was used to enhance drug release from DOX-loaded $\mathrm{Au} @ \mathrm{SiO}_{2}\left(\mathrm{Au} @ \mathrm{SiO}_{2}\right.$-DOX) for chemotherapy, while at higher irradiation intensity it also induced hyperthermia effects of the AuNRs. The $\mathrm{Au} @ \mathrm{SiO}_{2}$ platform thus kept both the unique functions of mesoporous silica nanoparticles and AuNRs, and also provided a new functionality: NIR light-controlled drug release. With the unique functions of both mesoporous silica nanoparticles and gold nanorods, the new $\mathrm{Au} @ \mathrm{SiO}_{2}$ platform could have wide and promising applications in cancer theranostics (Figure 11).

\section{Perspectives}

We have reviewed the research-level biomedical applications of AuNRs with a highlight on combined applications. The in vitro applications of AuNRs in bio-imaging, hyperthermia therapy and drug delivery have been well documented. A better understanding on how to optimize the properties of AuNRs for designing and preparing new AuNRs-based nanoplatforms would further help to promote their biomedical application. Currently, considerable efforts are devoted to combine both imaging and therapeutic functionalities into a single AuNRs-based system for more effective disease treatments. Surface modification and functionalization has played the key role in development of these theranostic platforms. Combined applications of AuNRs require participation and collaboration between chemists, biologists, materials scientists, and clinicians.

Though the current in vitro results are indeed encouraging, there are still issues that need to be addressed in order for AuNRs to be used for biomedical applications. More in vivo studies on their therapeutic efficacy, biocompatibility, and bio-distribution are required to make these techniques more clinically relevant.

\section{Acknowledgments}

Z. Zhang and J. Wang contributed equally to this work. We thank the Ministry of Science and Technology of China (National Basic Research Programs: 2011CB933401, 2012CB934003 and 2010CB934004), the National Science Foundation of China (31070854), and National Major Scientific Instruments Development Project (2011YQ03013406) for their financial support. 


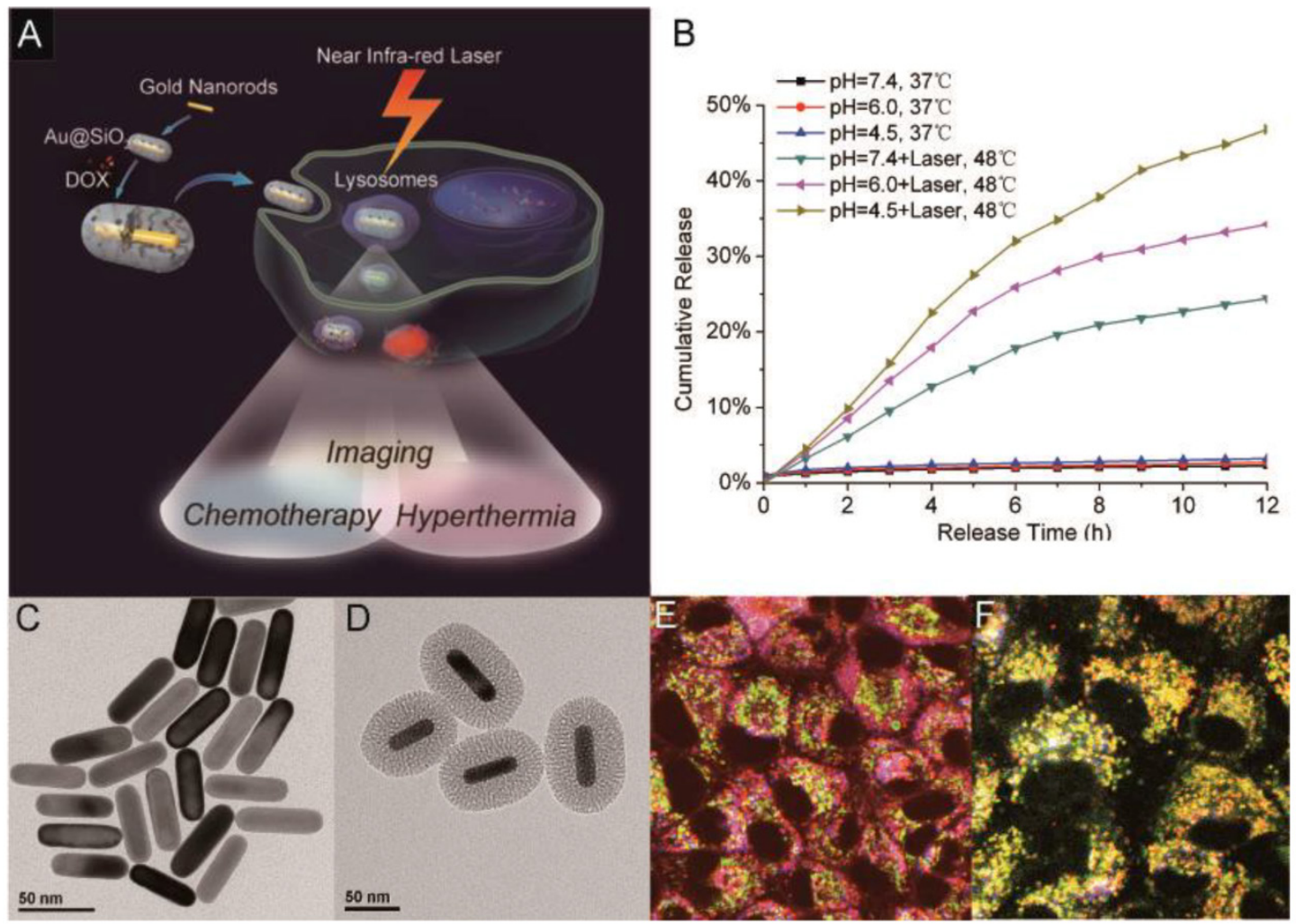

Fig II. Multifunctional platform of imaging, hyperthermia and drug delivery. (A) TOC image of the report; TEM image of (B) AuNRs and (C) Au@SiO ${ }_{2}$; (D) DOX release profiles from $\mathrm{Au} @ \mathrm{SiO}_{2}-\mathrm{DOX}$ with and without NIR laser irradiation at different pHs; (E, F) Intracellular localization of DOX (red) and $\mathrm{Au} @ \mathrm{SiO}_{2}$ (blue) with organelle-specific probes including Lyso-Tracker (green) and Mito-Tracker (green) using two-photon confocal microscope. Adapted with permission from [55].

\section{Conflict of Interest}

The authors have declared that no conflict of interest exists.

\section{References}

1. Tong L, Wei Q, Wei A, et al. Gold nanorods as contrast agents for biological imaging: optical properties, surface conjugation and photothermal effects. Photochem Photobiol. 2009; 85: 21-32.

2. Alkilany AM, Thompson LB, Boulos SP, et al. Gold nanorods: Their potential for photothermal therapeutics and drug delivery, tempered by the complexity of their biological interactions. Adv Drug Deliv Rev. 2011; 64: 190-9.

3. Ungureanu C, Kroes R, Petersen W, et al. Light interactions with gold nanorods and cells: implications for photothermal nanotherapeutics. Nano Lett. 2011; 11: 1887-94.

4. Sau TK, Murphy CJ. Seeded high yield synthesis of short Au nanorods in aqueous solution. Langmuir. 2004; 20: 6414-20.

5. Oldenburg AL, Hansen MN, Ralston TS, et al. Imaging gold nanorods in excised human breast carcinoma by spectroscopic optical coherence tomography. J Mater Chem. 2009; 19: 6407-11.

6. Chhetri RK, Kozek KA, Johnston-Peck AC, et al. Imaging three-dimensional rotational diffusion of plasmon resonant gold nanorods using polarization-sensitive optical coherence tomography. Phys Rev E Stat Nonlin Soft Matter Phys. 2011; 83: 040903.

7. Jung Y, Reif R, Zeng Y, et al. Three-dimensional high-resolution imaging of gold nanorods uptake in sentinel lymph nodes. Nano Lett. 2011; 11: 2938-43.

8. Wang H, Huff TB, Zweifel DA, et al. In vitro and in vivo two-photon luminescence imaging of single gold nanorods. Proc Natl Acad Sci USA. 2005; 102: 15752-6.
9. Durr NJ, Larson T, Smith DK, et al. Two-photon luminescence imaging of cancer cells using molecularly targeted gold nanorods. Nano Lett. 2007; 7: 941-5.

10. Imura $K$, Nagahara $T$, Okamoto $H$. Near-field two-photon-induced photoluminescence from single gold nanorods and imaging of plasmon modes. J Phys Chem B. 2005; 109: 13214-20.

11. Shobhit C, Sanjiv K, Singh N, et al. Development of chitosan oligosaccharide-modified gold nanorods for in vivo targeted delivery and non-invasive imaging by NIR irradiation. Bioconjug Chem. 2012; 23: 2173-82.

12. $\mathrm{Li} \mathrm{T}, \mathrm{Li} \mathrm{Q}, \mathrm{Xu} \mathrm{Y}$, et al. Three-dimensional orientation sensors by defocused imaging of gold nanorods through an ordinary wide-field microscope. ACS Nano. 2012; 6: 1268-77.

13. Niidome T, Shiotani A, Akiyama $Y$, et al. Theragnostic approaches using gold nanorods and near infrared light. Yakugaku Zasshi. 2010; 130: 1671-7.

14. Huang X, El-Sayed IH, El-Sayed MA. Applications of gold nanorods for cancer imaging and photothermal therapy. Methods Mol Biol. 2010; 624: 343-57.

15. Choi WI, Sahu A, Kim YH, et al. Photothermal cancer therapy and imaging based on gold nanorods. Ann Biomed Eng. 2012; 40: 534-46.

16. Manohar S, Ungureanu C, Van Leeuwen TG. Gold nanorods as molecular contrast agents in photoacoustic imaging: the promises and the caveats. Contrast Media Mol Imaging. 2011; 6: 389-400.

17. Jokerst JV, Thangaraj M, Kempen PJ, et al. Photoacoustic imaging of mesenchymal stem cells in living mice via silica-coated gold nanorods. ACS Nano. 2012; 6: 5920-30.

18. Li PC, Wei CW, Liao CK, et al. Photoacoustic imaging of multiple targets using gold nanorods. IEEE Trans Ultrason Ferroelectr Freq Control. 2007; 54: 1642-7.

19. Li PC, Wang CR, Shieh DB, et al. In vivo photoacoustic molecular imaging with simultaneous multiple selective targeting using antibody-conjugated gold nanorods. Opt Express. 2008; 16: 18605-15. 
20. Dickerson EB, Dreaden EC, Huang X, et al. Gold nanorod assisted near-infrared plasmonic photothermal therapy (PPTT) of squamous cell carcinoma in mice. Cancer Lett. 2008; 269: 57-66.

21. Tong L, Zhao Y, Huff TB, et al. Gold nanorods mediate tumor cell death by compromising membrane integrity. Adv Mater. 2007; 19: 3136-41.

22. Norman RS, Stone JW, Gole A, et al. Targeted photothermal lysis of the pathogenic bacteria, Pseudomonas aeruginosa, with gold nanorods. Nano Lett. 2008; 8: 302-6.

23. Wijaya A, Schaffer SB, Pallares IG, et al. Selective release of multiple DNA oligonucleotides from gold nanorods. ACS Nano. 2009; 3: 80-6.

24. Rai P, Mallidi S, Zheng X, et al. Development and applications of photo-triggered theranostic agents. Adv Drug Deliv Rev. 2010; 62: 1094-124.

25. Cobley CM, Chen J, Cho EC, et al. Gold nanostructures: a class of multifunctional materials for biomedical applications. Chem Soc Rev. 2011; 40: 44-56.

26. Stone J, Jackson S, Wright D. Biological applications of gold nanorods. Wiley Interdiscip Rev Nanomed Nanobiotechnol. 2011; 3: 100-9.

27. Ratto F, Matteini P, Centi S, et al. Gold nanorods as new nanochromophores for photothermal therapies. J Biophotonics. 2011; 4: 64-73.

28. Weissleder R. A clearer vision for in vivo imaging. Nat Biotechnol. 2001; 19: 316-7.

29. Wu G, Mikhailovsky A, Khant HA, et al. Synthesis, characterization, and optical response of gold nanoshells used to trigger release from liposomes. Methods Enzymol. 2009; 464: 279-307.

30. Sailor MJ, Park JH. Hybrid nanoparticles for detection and treatment of cancer. Adv Mater. 2012; 24: 3779-802.

31. Xie J, Lee S, Chen X. Nanoparticle-based theranostic agents. Adv Drug Deliv Rev. 2010; 62: 1064-79.

32. Wei A, Leonov AP, Wei Q. Gold nanorods: multifunctional agents for cancer imaging and therapy. Methods Mol Biol. 2010; 624: 119-30.

33. Murphy CJ, San TK, Gole AM, et al. Anisotropic metal nanoparticles: Synthesis, assembly, and optical applications. J Phys Chem B. 2005; 109: 13857-70.

34. Jana NR, Gearheart L, Murphy CJ. Seed-mediated growth approach for shape-controlled synthesis of spheroidal and rod-like gold nanoparticles using a surfactant template. Adv Mater. 2001; 13: 1389-93.

35. Gole A, Murphy CJ. Seed-mediated synthesis of gold nanorods: Role of the size and nature of the seed. Chem of Mater. 2004; 16: 3633-40.

36. Qiu Y, Liu Y, Wang L, et al. Surface chemistry and aspect ratio mediated cellular uptake of Au nanorods. Biomaterials. 2010; 31: 7606-19.

37. Alkilany AM, Shatanawi A, Kurtz T, et al. Toxicity and cellular uptake of gold nanorods in vascular endothelium and smooth muscles of isolated rat blood vessel: importance of surface modification. Small. 2012; 8:1270-8.

38. Lankveld DP, Rayavarapu RG, Krystek P, et al. Blood clearance and tissue distribution of PEGylated and non-PEGylated gold nanorods after intravenous administration in rats. Nanomedicine (Lond). 2011; 6: 339-49.

39. Boca SC, Astilean S. Detoxification of gold nanorods by conjugation with thiolated poly(ethylene glycol) and their assessment as SERS-active carriers of Raman tags. Nanotechnology. 2010; 21: 235601.

40. Xiao Y, Hong H, Matson VZ, et al. Gold nanorods conjugated with doxorubicin and cRGD for combined anticancer drug delivery and PET imaging. Theranostics 2012; 2: 757-68.

41. Black KC, Kirkpatrick ND, Troutman TS, et al. Gold nanorods targeted to delta opioid receptor: plasmon-resonant contrast and photothermal agents. Mol Imaging. 2008; 7: 50-7.

42. Yamashita S, Fukushima H, Akiyama Y, et al. Controlled-release system of single-stranded DNA triggered by the photothermal effect of gold nanorods and its in vivo application. Bioorg Med Chem. 2011; 19: 2130-5.

43. Oyelere AK, Chen PC, Huang X, et al. Peptide-conjugated gold nanorods for nuclear targeting. Bioconjug Chem. 2007; 18: 1490-7.

44. Park H, Lee S, Chen L, et al. SERS imaging of HER2-overexpressed MCF7 cells using antibody-conjugated gold nanorods. Phys Chem Chem Phys. 2009; 11: 7444-9.

45. Gorelikov I, Matsuura N. Single-step coating of mesoporous silica on cetyltrimethyl ammonium bromide-capped nanoparticles. Nano Lett. 2008; 8: 369-73.

46. Slowing II, Vivero-Escoto JL, Wu CW, et al. Mesoporous silica nanoparticles as controlled release drug delivery and gene transfection carriers. Adv Drug Deliv Rev. 2008; 60: 1278-88.

47. Wu SH, Hung Y, Mou CY. Mesoporous silica nanoparticles as nanocarriers. Chem Commun (Camb). 2011; 47: 9972-85.

48. Xu L, Liu Y, Chen Z, et al. Surface-engineered gold nanorods: promising DNA vaccine adjuvant for HIV-1 treatment. Nano Lett. 2012; 12: 2003-12.
49. Bayer CL, Chen YS, Kim S, Mallidi S, Sokolov K, Emelianov S. Multiplex photoacoustic molecular imaging using targeted silica-coated gold nanorods. Biomed Opt Express. 2011; 2: 1828-35.

50. Chen YS, Frey W, Kim S, et al. Silica-coated gold nanorods as photoacoustic signal nanoamplifiers. Nano Lett. 2011; 11: 348-54.

51. Huang $\mathrm{P}$, Bao L, Zhang C, et al. Folic acid-conjugated silica-modified gold nanorods for X-ray/CT imaging-guided dual-mode radiation and photo-thermal therapy. Biomaterials. 2011; 32: 9796-809.

52. Luo T, Huang P, Gao G, et al. Mesoporous silica-coated gold nanorods with embedded indocyanine green for dual mode X-ray CT and NIR fluorescence imaging. Opt Express. 2011; 19: 17030-9.

53. Chen YS, Frey W, Kim S, et al. Enhanced thermal stability of silica-coated gold nanorods for photoacoustic imaging and image-guided therapy. Opt Express. 2010; 18: 8867-78.

54. Wang TT, Chai F, Wang CG, et al. Fluorescent hollow/rattle-type mesoporous $\mathrm{Au} @ \mathrm{SiO}_{2}$ nanocapsules for drug delivery and fluorescence imaging of cancer cells. J Colloid Interface Sci. 2011; 358: 109-15.

55. Zhang Z, Wang L, Wang J, et al. Mesoporous silica-coated gold nanorods as a light-mediated multifunctional theranostic platform for cancer treatment. Adv Mater. 2012; 24:1418-23.

56 Wang L, Liu Y, Li W, et al. Selective targeting of gold nanorods at the mitochondria of cancer cells: implications for cancer therapy. Nano Lett. 2011; 11: 772-80.

57 Rayavarapu RG, Petersen W, Hartsuiker L, et al. In vitro toxicity studies of polymer-coated gold nanorods. Nanotechnology, 2010; 21:145101-10.

58 Hauck TS, Ghazani AA, Chan WC. Assessing the effect of surface chemistry on gold nanorod uptake, toxicity, and gene expression in mammalian cells. Small. 2008; 4:153-9.

59 Alkilany AM, Nagaria PK, Hexel CR, et al. Cellular uptake and cytotoxicity of gold nanorods: molecular origin of cytotoxicity and surface effects. Small. 2009; 5: 701-8.

60. Puvanakrishnan P, Diagaradjane P, Kazmi SM, et al. Narrow band imaging of squamous cell carcinoma tumors using topically delivered anti-EGFR antibody conjugated gold nanorods. Lasers Surg Med. 2012; 44: 310-7.

61. Yang S, Ye F, Xing D. Intracellular label-free gold nanorods imaging with photoacoustic microscopy. Opt Express. 2012; 20: 10370-5.

62. Kirui DK, Krishnan S, Strickland AD, et al. PAA-derived gold nanorods for cellular targeting and photothermal therapy. Macromol Biosci. 2011; 11: 779-88.

63. Rejiya CS, Kumar J, V R, et al. Laser immunotherapy with gold nanorods causes selective killing of tumour cells. Pharmacol Res. 2012; 65: 261-9.

64. Li Z, Huang P, Zhang X, et al. RGD-conjugated dendrimer-modified gold nanorods for in vivo tumor targeting and photothermal therapy. Mol Pharm. 2010; 7: 94-104

65. Zhou W, Shao J, Jin Q, et al. Zwitterionic phosphorylcholine as a better ligand for gold nanorods cell uptake and selective photothermal ablation of cancer cells. Chem Commun (Camb). 2010; 46: 1479-81.

66. Torchilin V. Multifunctional nanocarriers. Adv Drug Deliv Rev. 2006; 58 : 1532-55.

67. Torchilin V. Multifunctional and stimuli-sensitive pharmaceutical nanocarriers. Eur J Pharm Biopharm. 2009; 71: 431-44.

68. Timko BP, Dvir T, Kohane DS. Remotely triggerable drug delivery systems. Adv Mater. 2010; 22: 4925-43.

69. Mayer G, Heckel A. Biologically active molecules with a "light switch". Angew Chem Int Ed Engl. 2006; 45: 4900-21.

70. Takahashi H, Niidome Y, Yamada S. Controlled release of plasmid DNA from gold nanorods induced by pulsed near-infrared light. Chem Commun (Camb). 2005;: 2247-9.

71. Shiotani A, Mori T, Niidome T, et al. Stable incorporation of gold nanorods into $\mathrm{N}$-isopropylacrylamide hydrogels and their rapid shrinkage induced by near-infrared laser irradiation. Langmuir. 2007; 23: 4012-8.

72. Yamashita S, Fukushima $\mathrm{H}$, Niidome $\mathrm{Y}$, et al. Controlled-release system mediated by a retro Diels-Alder reaction induced by the photothermal effect of gold nanorods. Langmuir. 2011; 27: 14621-6.

73. Chakravarthy KV, Bonoiu AC, Davis WG, et al. Gold nanorod delivery of an ssRNA immune activator inhibits pandemic H1N1 influenza viral replication. Proc Natl Acad Sci USA. 2010; 107: 10172-7.

74. Min Y, Mao C, Xu D, et al. Gold nanorods for platinum based prodrug delivery. Chem Commun (Camb). 2010; 46: 8424-6.

75. Huang $\mathrm{X}$, El-Sayed $\mathrm{IH}$, Qian $\mathrm{W}$, et al. Cancer cell imaging and photothermal therapy in the near-infrared region by using gold nanorods. J Am Chem Soc. 2006; 128: 2115-20.

76. Huff TB, Tong L, Zhao Y, et al. Hyperthermic effects of gold nanorods on tumor cells. Nanomedicine (Lond). 2007; 2: 125-32. 
77. Choi J, Yang J, Bang D, et al. Targetable gold nanorods for epithelial cancer therapy guided by near-IR absorption imaging. Small. 2012; 8: 746-53.

78. Yi DK, Sun IC, Ryu JH, et al. Matrix metalloproteinase sensitive gold nanorod for simultaneous bioimaging and photothermal therapy of cancer. Bioconjug Chem. 2010; 21: 2173-7.

79. Kuo WS, Chang CN, Chang YT, et al. Gold nanorods in photodynamic therapy, as hyperthermia agents, and in near-infrared optical imaging. Angew Chem Int Ed Engl. 2010; 49: 2711-5.

80. Bonoiu AC, Bergey EJ, Ding $\mathrm{H}$, et al. Gold nanorod-siRNA induces efficient in vivo gene silencing in the rat hippocampus. Nanomedicine. 2011; 6: 617-30.

81. Hauck TS, Jennings TL, Yatsenko T, et al. Enhancing the toxicity of cancer chemotherapeutics with gold nanorod hyperthermia. Adv Mater. 2008; 20: 3832-8.

82. Xiao Z, Ji S, Shi J, et al. DNA self-assembly of targeted near-infrared-responsive gold nanoparticles for cancer thermo-chemotherapy. Angew Chem Int Ed Engl. 2012; 51: 11853-7. 